\title{
Renegotiations of Canadian Space in Contemporary CBC Audio Distribution Models
}

\author{
The organization of space and time effected by these developments - by means of \\ 'content-free' media such as the telegraph and the train, as much as the newspaper or \\ photograph - structures the material forms and limits of knowledge, as well as our \\ relationships with place and with one another. Here Innis reveals the limits and \\ inadequacies of analyzing power in terms of representation. (Berland 1999: 291)
}

This paper treats the Canadian Broadcasting Corporation's (CBC) online ventures as examples of the national public broadcaster's continued negotiation of Canadian space. More specifically, the paper looks at the online streaming and podcasting of English language radio broadcast content. This paper accounts for CBC Radio One's distribution of audio programming - historically by way of national broadcasts and more recently by way of online streaming and podcast archives - as models of Canadian cultural transmission, which marginalize outlying Canadian regions in relation to production centres in Toronto and Montréal. This paper treats CBC Radio One's collection, assemblage and transmission of programming as better indicators of the inequalities between production centers and outlying regions than any particular programming content. With focus on the most recent incarnation of the $\mathrm{CBC}$ radio morning interview show, $Q$, and drawing from Canadian communication studies, I will outline how the podcasting of English language $\mathrm{CBC}$ radio programming both rearticulates the broadcaster's history and presence as a central manager of Canadian stories, and provides audiences with opportunities to actively undermine this centralized management.

Podcasting involves the provision of updated online archives of recordings, accessible for download and playback by computer users at a time of their choice. The $\mathrm{CBC}$ has been making and distributing podcasts since 2005 (Committee on Canadian Heritage 2008: 52). The CBC delivers over two million podcasts every month (Lacroix 2009). One of these podcasts is $Q$, a program where host Jian Ghomeshi interviews predominantly Canadian cultural producers, politicians and media figures, emphasizing their link to Canada. For example, Ghomeshi interviewed Heritage Minister James Moore inquiring about the government's funding of contemporary Canadian art (CBC Radio 2009a). He spoke to Margaret Atwood about being a Canadian writer (CBC Radio 2009c). He interviewed Nova Scotia-born comedian Ron James, inquiring about his appeal to everyday Canadians (CBC Radio 2009a), and he asked Leonard Cohen about his sold-out shows in Saskatoon, Saskatchewan and London, Ontario (CBC Radio 2009b). 
Questions concerning Canadianness are commonplace on the CBC, a network designed to stake claims on Canadian cultural space. As noted in the Royal Commission on Radio Broadcasting Report, "In a country of the vast geographical dimensions of Canada, broadcasting will undoubtedly become a great force in fostering a national spirit and interpreting national citizenship" (1929: 6). The 1929 Commission Report, which gave birth to the CBC's predecessor, the Canadian Radio Broadcasting Commission (CRBC), addressed the need for a national radio network in response to increasingly frequent broadcasts of American signals into Canadian territory. The context surrounding the report was described twenty years later in The Royal Commission on National Development in the Arts, Letters, and Sciences: "Many Canadians in the 1920's ... began to fear that cultural annexation would follow our absorption into the American radio system just as surely as economic and even political annexation would have followed absorption into the American railway system fifty years earlier" (1951: 24). The CRBC's first action - the purchase of Canadian National Railway and Canadian Pacific Railway telegraph stations in Ottawa, Vancouver and Moncton (CRTC 2008; Vipond 1994: para. 39) - reflected federal attempts to deploy a national media network along the same lines as the transportation network which accompanied confederation. However, as outlined by Canadian media historian Mary Vipond, the Canadian national broadcasting network began to show internal, centralizing tendencies from its beginnings:

The Assistant Commissioners and regional Advisory Committees who according to the 1932 [Radio Broadcasting] Act were supposed to provide the Commission with advice regarding regional programming were never appointed, and in practice all decisions about programs on the national network were made by two officials based in Toronto and Montréal. (1994: para. 56)

While Canada's first mass media network was organized in response to the potential dominance of American broadcasting, I would like to outline some of the power relations that developed alongside Canada's centrally operated national public broadcaster.

In addition to being a producer and distributer of Canadian media content, the CBC continues to be a central manager of Canadian geographic space. The broadcaster, like the railroad network before it, orients outlying Canadian regions in relation to production centres located in Toronto and Montréal. This arrangement persists despite the reference to regional representation in the CBC's mandate (Broadcasting Act 1991) and despite the inclusion of audio content obtained from outlying Canadian regions. The broadcasting centres maintain their control because of their commitment to represent all Canadian regions. When English Canadian shows like $Q$ inquire about the regional experience or origins of their guests, the Canadian Broadcasting Centre in Toronto reasserts its centrality; whether or not Toronto provides the backdrop for a particular story, the Canadian Broadcasting Centre remains the place where regional stories and experiences are manufactured into programs, and the place from which these programs are redistributed nationwide. 
The work of Harold Innis, as read through Jody Berland (1999) and Kevin Dowler (1999), provides a model of empires - or extensive institutions of power - that stresses the effects of resource collection, manufacture and distribution. Canadian empire derives from the arrangement of networks that mobilize resources in manufacturing centres and distribute manufactured products to peripheral regions. At least two of Innis's observations about railway networks inform analyses of the power accompanying communication networks. First, the expansion of railway lines in the late $19^{\text {th }}$ century was synchronic and parallel with the formation of Canada because railways allowed for peripherally situated resources to be easily transported to manufacturing centres in Ontario and Québec, and for manufactured goods to be distributed to the peripheral regions in turn. Second, because railways are bidirectional, their extension across western Canada made the peripheral, resource-offering communities and the central, manufacturing communities codependent in unequal ways. The manufacturing centres functioned as both the geographic point of orientation for the railway lines and the manufacturer and distributor of cultural products to the peripheral regions via the train lines. The deployment of the railway accompanied Canada's efforts to both overcome its colonial dependence on Britain and avoid annexation by the emergent American economic and cultural centre by arranging provinces and regions around a new Canadian economic, political and cultural centre.

Jody Berland stresses the power relations inherent to centralizing networks by emphasizing the relatively subordinate position of the margin, or the space "drawn into the axes of imperial economy, administration, and information that remains 'behind' (to put it in temporal terms) or 'outside' (in terms of industrial and political power)" (1999: 288). A focus on the dynamics of the early Canadian distribution network and the unequal tension between production centres and peripheral resource-offering communities speaks to the present form and dynamics of the CBC. The regionally-committed, centralized broadcaster collects stories, experiences and cultural productions from across the country and manufactures the collected content into shows at the Canadian Broadcasting Centres before redistributing programming to the peripheral, or marginal, communities through its media network. While CBC producers and affiliates in non-central and outlying regions $d o$ produce programs which address regional concerns and air exclusively in particular regions, flagship programs like $Q$ address national and regional topics for a national audience; it is the national programs' treatments of Canadian regions that reach all regions of the country. The CBC's commitment to regional content-whatever that content is - rearticulates the production centre's privileged place in the national media network and national cultural landscape. While programming manufactured in Canadian Broadcasting Centres reflect stories and concerns from all regions of the country, CBC's model of program distribution could be imagined as a cascade where flagship programs such as $Q$, produced in the Canadian Broadcasting Centres, make their way "down" to regional airwaves while programming made by local affiliates airs primarily in its locality of origin.

The hegemonic power of the network's organization is most apparent in underrepresented communities' requests for representation on the CBC. Responding to claims that alternative 
media in Canada serve as a potentially subversive "hinterland" to mainstream media, Kevin Dowler stresses that "the margin ... cannot be viewed as a source of dissent. Rather, protest takes the form of a demand - that government step in ... to support cultural production" (1999: 350). Likewise, the expressed concerns of peripheral communities underrepresented on the $\mathrm{CBC}$ can be recognized as requests for the $\mathrm{CBC}$ to step in and use regional cultural resources as grist for the $\mathrm{CBC}$ mill. The rhetoric of regionalism in the $\mathrm{CBC}$ mandate, and any representation of diverse regions in $\mathrm{CBC}$ content, are testament to the broadcaster's celebration of its own success in gathering content widely, assembling it uniformly and redistributing it just as widely. The CBC's dedication to regionalism is a strategy of centralization.

The CBC's increasing use of podcast archives as a means of program distribution does not mark a rupture from this centralizing model of cultural production and distribution; podcasting enables a perpetuation of it. The CBC has always engaged with new media. It was Canada's first national radio network in the early days of radio, and a coast-to-coast television broadcaster in the early days of television (CBC/Radio-Canada 2010). With the advent of podcasting, the CBC's role changes from a manager of broadcast air time to a manager of its own digital archives. Throughout this evolution, however, the broadcaster's role as the privileged central agent in the collection, manufacture and distribution of radio content is essentially maintained. Whether or not centrally produced flagship programs like $Q$ are overrepresented in the CBC's archives, the historical inequalities between underrepresented peripheral regions and central cultural producers are echoed in the relationship between the regional audiences of $C B C$ broadcasts and the CBC's podcast-collecting archivists. Inequalities between marginalized Canadian regions and central Canadian cultural producers are expressed in exchanges surrounding one of the "Frequently Asked Questions" posted on CBC's website, CBC.ca: "Why are you changing your regional podcasts?" The answer posted by the CBC outlines what their podcast producers were in the habit of doing and what they plan to do. It is worth noting at length:

\footnotetext{
... it was onerous and time-consuming to collect audio from a week's worth of regional programming from a number of shows. [The regional podcast producers'] primary responsibilities are to their shows, not the [regionally aired] podcasts. Thus, we decided that moving to a show-based podcast format would work better for the podcast producers' workloads .... We are gradually moving all of our weekly pan-region podcasts to daily regional show podcasts. (CBC.ca, emphasis added)
}

This response shows that the $\mathrm{CBC}$, which began as an organization for collecting regional stories and experiences, has habitually collected content not only from Canadian regions and their constituencies, but from various $C B C$ programs as they air in different regions. The programming is manufactured into the podcasts which are archived online. CBC has since abandoned this strategy, focusing instead on arranging content according to shows as opposed to regions. Finally, admitting that their podcast archives are works-in-progress, the CBC promises to re-prioritize regional content (that is, $\mathrm{CBC}$ content as it was aired and heard in particular regions) by gradually archiving that thoroughly. 
These exchanges concerning the assemblage of English language audio podcasts illustrate how the CBC's continuing negotiations with regional constituencies and experiences are framed by CBC's success in making its programming stand in for regional constituencies and experiences. In negotiating the degree to which regional content will be archived as a podcast, the CBC is not answering the geographic or economic concerns of particular regions of the country, but responding instead to the groups of regional listeners organized according to the Corporation's regional programming schedules. Here, the central role of the Toronto- and Montréal-based production centres in the national public media network is reasserted in the CBC's ongoing maintenance of its online archives.

Old media formats persist alongside new media; live radio persists alongside podcasting. But the CBC's attention to podcasting as a potential avenue of Canadian nationalist culture is accompanied by a re-articulation of the gap between centrally located cultural producers and members of the community of listeners. In the case of podcasting, the physical space between Toronto- and Montréal-based production centres and the peripheral regions is accompanied by a time lapse between a radio show's production and its consumption by the listener. Yet these arrangements still constitute a dynamic of relatively unequal negotiations between underrepresented outlying regions and the network's production centres. In what remains, I will contrast CBC Radio's current flagship morning talk show, $Q$, with one of its predecessors, with attention to the avenues podcasting presents for struggles over existing Canadian media arrangements and continued negotiations of Canadian space.

In contrast to CBC's growing role as a manager of public digital archives, $\mathrm{CBC}$ has historically made use of its network to provide shared Canadian time: time when audiences in Canada's six time zones could knowingly listen to the same national broadcast. From 1982 to 1997, for instance, Peter Gzowski's Morningside aired live, weekdays from nine to noon, Eastern Standard Time. Like Ghomeshi, Gzowski - who was often referred to as "Mr. Canada" (O'Malley and Wilkins 2002) - talked to guests from across the country about their experiences of its various regions. Gzowski was Mr. Canada in the most important sense because he shared the time of the broadcast with its national audience. Testament to the importance of simultaneity as a strategy for Morningside's symbolic mobilization of Canadians is the sense of loss, of a lack of presence, in the website which now archives bits of the show. The Morningside archive has the feeling of a memorial—not just because Gzowski is dead (although audio segments of Gzowski's voice and his guests' addresses of "good morning, Peter" are cued with each navigation through the site). Rather, the Morningside archive feels like death because Morningside was produced to be heard live. What is heard on $\mathrm{CBC}$ radio has not changed that much. The guests and questions presently on $Q$ are not significantly different from the content of Morningside. However, $Q$, the first show of its kind to be podcasted, marks both a repetition and a retooling of the CBC's centralizing organization of Canadian mass culture. Never before has a CBC Radio interview show been either more convenient to access or less dependent on the synchronized attention of audiences. 
This ability to reach listeners when they choose to be reached poses a significant advantage and challenge for a broadcaster responsible for addressing a nation that spans six time zones.

Radio timeslots and broadcasting radiuses are becoming increasingly less significant in the Internet age. Still, as the online national broadcaster continues to negotiate the challenges of Canadian space, existing accommodations of vast Canadian space-time zones resurface online. Today, simultaneous "live" streams of regional radio broadcasts provide online listeners with aired programming from every Canadian time zone. While shows like Morningside were aired once nationwide, contemporary $\mathrm{CBC}$ morning radio shows are aired at staggered times, according to time zones. CBC's website allows users to choose which airing or airings of the program they access. This means, for instance, that an Atlantic Canadian who misses part of Radio 2 Morning can access a later, western airing of the show. While pan-regional broadcasts synchronized Canadians' listening experiences by broadcasting in every Canadian region simultaneously, online streams of regionally staggered programming allow online audiences to navigate and arrange content according to previously fractured or incongruent combinations. While CBC podcast archives do not facilitate synchronized audienceship, podcasts do serve the CBC's strategy of central authority over the mediation of Canadian space by being the official compressions of regional experiences of CBC programming. By replacing a multiplicity of potential listening experiences with an official version, podcast producers iron out the disjointedness experienced by the online listener who pulls from different live streams.

The nationally formative struggles between the centres and margins of Canadian empirestruggles which developed alongside technological negotiations of Canadian space - continue as CBC radio reorganizes its content into podcasts. While its central assemblage of previously aired content marks the network's renewed commitment to asserting its central role in Canadian cultural production, podcasting also marks new avenues of agency for CBC audiences. Not only can podcast users choose which podcasts they listen to, but, by way of personal media devices, podcast audiences can choose to rewind, repeat, fast-forward and compare material from any number and variety of podcasts. Walter Benjamin described the motion picture's potential for soliciting audiences' critical engagement with their world, arguing that early $20^{\text {th }}$-century film's assemblage of various contrasting points of view invited audiences to look beyond the actors or characters represented in a film - the content - and identify instead with the reality-testing operations of the camera (1988: 229-30). Likewise, podcasted assemblages of aired CBC content put audiences in the position of testers. Podcast users remain "marginal" in the sense that their engagement with $\mathrm{CBC}$ programs lags behind the $\mathrm{CBC}$ 's production and airing of these programs. Yet, given users' ability to negotiate podcast archives - to select, sample, reactivate and combine any quantity and variety of $\mathrm{CBC}$ audio material - the distinction between the work of cultural producers and the activities of audience members is beginnings to blur. Digital technologies such as live audio streaming and podcasting do not eliminate the Canadian Broadcasting Centres' central positions in the now online national media network. These digital methods of program distribution do, however, complicate the CBC's role as a national broadcaster. CBC producers 
still collect, assemble and release content pertaining to or originating from outlying regions; the avenues by which these assemblages are distributed, however, are increasingly open to the navigations and reorganizations of online audiences. As audience members become users, a national media network which operates according to a particular dynamic of content collection and program distribution loses the final cut, and with it some of its overarching organizational power over the national media environment.

CBC Radio remains Canada's most widely accessible producer of nationalist audio media content. Attention to the ways and means by which CBC collects, assembles and distributes its content, and a focus on the centralizing dynamics of the broadcaster's mediation of Canadian regions, are as revealing of the Canadian cultural landscape as any mediated representations of the country - these arrangements are as meaningful as any particular kind of Canadian content. I have attempted to show how the online $\mathrm{CBC}$, in its problematic efforts to represent marginalized Canadian regions and constituencies, is merely the newest articulation of tensions which continue to shape the nation and the national culture: exchanges between dominant regions and the country that surrounds them, and negotiations of geography by the technologies deployed to facilitate and promote the nation.

\section{References}

Benjamin, Walter. 1988. The work of art in the age of mechanical reproduction. In Illuminations: Essays and Reflections, edited by Hannah Arendt, 217-51. New York: Harcourt Brace and World.

Berland, Jody. 1999. Space at the margins: Critical theory and colonial space after Innis. In Harold Innis in the New Century: Reflections and Refractions, edited by W. Buxton and C. R. Acland, 281-308. Kingston: McGill-Queens University Press.

Broadcasting Act 1991, c.11. http://laws.justice.gc.ca/eng/B-9.01/page-1.html\#anchorbo-ga:1_I-gb:s_3.

Canadian Broadcasting Corporation (CBC). CBC digital archives: morningside. http://archives.cbc.ca/programs/502/ [accessed 1 March 2010].

Canadian Radio-television and Telecommunications Commission (CRTC). CRTC origins. CRTC. http://www.crtc.gc.ca/eng/backgrnd/brochures/b19903.htm [accessed 10 February 2010].

CBC.ca. Podcasting frequently asked questions. Canadian Broadcasting Corporation. http://www.cbc.ca/podcasting/faq.html\#FAQ17 [accessed 1 March 2010].

CBC Radio. 2009a. James Moore and Ron James on Q. podcast radio program. Toronto: CBCRadio. 24 September 2009. http://www.cbc.ca/podcasting/pastpodcasts.html?42\#ref42 [accessed February 10, 2010].

2009b. Leonard Cohen on Q. podcast radio program. Toronto: CBC Radio. 27 August 2009. http://www.cbc.ca/podcasting/pastpodcasts.html?42\#ref42 [accessed 4February 2010].

2009c. Margaret Atwood on Q. podcast radio program. Toronto: CBC Radio. 11 November 2009. http://www.cbc.ca/podcasting/pastpodcasts.html?42\#ref42 [accessed 4 February 2010]. 
CBC/Radio-Canada. CBC/Radio-Canada Milestones. CBC Radio. http://www.cbc.radio canada.ca/history/1950s.shtml [accessed 1 February 2010].

Committee on Canadian Heritage. 2008. CBC/Radio Canada: Defining Distinctiveness in the Changing Media Landscape. Ottawa, ON: Government Printing Office.

Dowler, Kevin. 1999. Early Innis and the post-Massey era in Canadian culture. In Harold Innis in the New Century: Reflections and Refractions, edited by W. Buxton and C. R. Acland, 339-54. Kingston: McGill-Queens University Press.

Lacroix, H. T. 2009. Speaking Notes for Hubert T. Lacroix, President and CEO, CBC/Radio-Canada, at the CBC/Radio-Canada Annual Public Meeting. http://www.cbc.radiocanada.ca/speeches/20090923a.shtml.

O’Malley, M. and K. Wilkins. 2002. Peter Gzowski: Broadcasting's 'Mister Canada'. CBCNews Online. http://www.cbc.ca/news/obit/gzowski_peter/ [accessed 1 March 2010].

Royal Commission on National Development in the Arts, Letters and Sciences (1951). Report of the Royal Commission on National Development in the Arts, Letters and Sciences. Collections Canada. http://collectionscanada.gc.ca/massey/h5-400-e.html.

Royal Commission on Radio Broadcasting. 1929. Report of the Royal Commission on Radio Broadcasting. Ottawa, ON: King's Printer.

Vipond, M. 1994. The beginnings of public broadcasting in Canada: the CRBC, 1932-1936. Canadian Journal of Communication 19(2). http://www.cjc-online.ca/index.php/ journal/article/viewArticle/806/712 [accessed 1 March 2010]. 